\title{
Ligature Mark in Hanging - Gross and Histopathological Examination with Evaluation and Review
} \author{
Arumalla $^{5 *}$ \\ ${ }^{1}$ Department of Forensic Medicine, SVIMS - Sri Padmavathi Medical College for Women \\ ${ }^{2}$ Department of Forensic Medicine, Viswabharathi Medical College \\ ${ }^{3}$ Department of Laboratory Medicine \& Blood Bank, Prince Mutaib Bin Abdul Aziz Hospital \\ ${ }^{4}$ Department of Forensic Medicine, Kurnool Medical College \\ ${ }^{5}$ Department of Biochemistry, Esic Medical College
}

K. Jyothi Prasad', M. Abdul Khalid², KhaderFaheem. N³ , B. Lakshmi Narayana ${ }^{4}$, Veerendra Kumar

*Corresponding author: Dr. Veerendra Kumar Arumalla, Md, Assistant Professor of the Department, Department of Biochemistry, Esic Medical College, Tamil Nadu, India; E-mail: drveerendraarumalla@gmail.com

\begin{abstract}
Background: Hanging is one of the most common methods of approach in case of suicidal deaths in India. Virtually all hangings are suicides until otherwise it is proved contrary. The ligature mark plays a major role in deriving the important findings to lead investigation. The correlation of external, internal findings help to establishing the crucial facts in cases of hanging.
\end{abstract}

Aims \& Objectives: To study various patterns of ligature mark. To differentiate cases of antemortem hanging with postmortem.

Materials \& Methods: A study carried out in Departments of Forensic Medicine and Pathology, S.V.Medical College, Tirupati from January 2010 to December 2013 with 83 cases of asphyxial deaths due to hanging. A thorough external and internal examination of ligature mark was performed in all the cases.

Results: A total of 83 cases were notified. Majority, 37(44.5\%) of cases belong to 3rd decade (21-30 yrs). Males are common victims - 52(62.6\%). Complete hanging was commonest type - 76(91.56\%). Chunni was the commonest material - 25(31.12\%). Single ligature mark was common $-80(96.3 \%)$. Gross examination revealed soft tissue changes in 23(27.71\%) cases. Microscopic examination - breaking, wrinkling and compression of skin along with micro hemorrhages and inflammatory changes in subcutaneous tissues were notified.

Conclusion: The examination of corpse in cases of hanging is made easy by correlating current observation with the following finding. The correlation of external, internal and microscopic findings leads to easy formulation of final opinion these cases. It also, to some extent helps to delineate antemortem cases of hanging with postmortem cases.
Received Date: January 25, 2016

Accepted Date: March 22, 2016

Published Date: March 28, 2016

Citation: Arumalla, V.K., et al. Ligature Mark in Hanging - Gross and Histopathological Examination with Evaluation and Review (2016) J Addict Depend 2(1): 6571.

\section{DOI: $10.15436 / / 2471-061 X-16-018$}

Keywords: Hanging; Ligature material; Microscopic examination; Suicidal deaths

\section{Introduction}

Hanging is one of the commonest methods of approach in case of suicidal deaths in India. Eight lakh cases of suicides have been reported all over the world in the year 2012 and 1,34,600 suicide cases have been reported in India in the same year amongst which 41,726 (31\%) were victims of hanging. Thus, hanging was found out to be second most common cause of suicidal death in India in the year 2012. The most common cause being death by pesticide intake ${ }^{[1]}$. Virtually all hangings are suicides until otherwise it is proved contrary ${ }^{[2]}$. It is a form of ligature strangulation in which force applied to the neck is derived from the gravitational pull of the weight of the body or the part of the body ${ }^{[3]}$. The factor of suspension differentiates hanging from strangulation by ligature; the latter being caused by application of a ligature of the neck in such a way that the force acting upon it is other than the weight of the body ${ }^{[4]}$. The ligature material can be any household substance. A single knot with a running noose, fixed knot by a granny, reef knot or a simple loop is found in cases of hanging ${ }^{[5]}$. The nature of ligature mark depends upon the material and position of ligature used and the time of suspension of body after death. If the ligature material is soft and is removed immediately after death, the mark might be absent in such cases. Thick and long beard or clothes on neck may lead to formation of a dull and ill formed ligature mark. 
Thus, the ligature mark becomes a crucial aid in diagnosis and evaluation of the corpse. Hence, examination of ligature material and mark becomes an indispensable part of autopsy. Ligature produces a mark as a furrow or groove in the tissue which is pale initially, turns yellow or yellowish brown and becomes dry; it will be hard on touch, parchment like due to drying of slightly abraded skin. Oozing of blood and serous fluid is also occasionally observed. With progression of time, the furrow dries and becomes brownish Grey. The ligature mark is more detectable in cases where the ligature is narrow and material is hard. The suspension time is directly proportional to the detectability of ligature mark. The contrast between reddish and paler bands of skin can be accentuated in a properly taken photograph. Thus, multiple pictures are taken at different times till autopsy is completed - this technique is called as "bracketing" or color saturation $^{[6]}$. Usually single line or mark is found. But, multiple marks may also be seen in cases of spiral turns, multiple turns around neck or upward displacement of material after application due to fall. In majority of cases the mark is found above thyroid cartilage between larynx and chin and will be oblique in direction. The mark is directed upwards, parallel to the line of mandible and is incomplete at the back with an ill-defined impression of the knot at the point of suspension, which is usually at mastoid process of one side. Sometimes, mark may be present on or below thyroid cartilage in case of partial hanging. The mark will be circular and oblique if a ligature is passed around the neck more than once. Inverted "V" shaped mark is found near the knot ${ }^{[7]}$.

The line of congestion may be seen along course of a furrow, which is considered significant and is interpreted as a vital reaction by Polson ${ }^{[8]}$. Thus, the line of congestion is a sign of ante mortem hanging. Here exists another challenge in front of forensic experts to qualify the case of hanging as ante mortem or post mortem i.e., fabricated scene of hanging in case of homicides. The diagnosis of ante mortem hanging is only a measure of probability when only gross features are observed that too in the absence of strong proof to the contrary ${ }^{[9]}$. The triad of probability consists of - (i) Streaks or bands of reddened or pink tissue (ii) a pattern that may disclose imprint of ligature (iii) canting / sloping of the markings upwards towards the back of neck ${ }^{[7]}$. Even though the triad of features is considered to be characteristic, the measure of probability lacks a fair ground to lay a foundation of differentiation between ante mortem and post mortem hanging. The ligature mark and gross features only may not be necessarily the deciding factors. Similar ligature mark as of hanging can also be produced by means of fabrication by applying a ligature within 24 hours or even later after death of an individual. Thus, any kind of mark may not be conclusive evidence to that - the hanging took place during life ${ }^{[10]}$. Hence, a detailed internal examination of neck structures (soft tissue, bones $\&$ cartilages) and histopathological examination of the mark and internal neck structures gives additional and necessary information in these cases. The histopathological examination reveals the presence of effusion of red cells, congested blood vessels, hemorrhages, tissue reaction etc., in cases of ante mortem hanging. Though absence of the above findings does not exclude ante mortem hanging, its presence plays a major role in establishing the facts in cases of hanging ${ }^{[1]}$.

In the present study the authors have tried to make an attempt to study external, internal, gross features of neck correlating these findings with histomorphological observations in respective cases to establish the exact mode and nature of death of the individual.

\section{Aims and objectives}

1. To study various patterns and variations in ligature marks in case of hanging in comparison with age, sex, social status, mode of hanging, type of knot and type of ligature material.

2. To ascribe whether the hanging is ante mortem or post mortem by examining and correlating the scene of crime and studying gross and histomorphological features of the ligature mark.

\section{Materials and Methods}

The present study was carried out in the Department of Forensic medicine in collaboration with Department of Pathology at S.V.Medical College, Tirupati. A total of 83 cases of asphyxial deaths due to hanging were enumerated and an extensive study was performed over a period of four years from January - 2010 to December - 2013. A thorough external examination was conducted in the mortuary starting with estimation of age, ascertaining sex of individual, bodily deformity if any, position of body, clothing, scalp and other hair, stains (salivary, blood, other fluids and ejaculated semen). Emphasis was made over ligature mark and material. A meticulous local external examination of neck was done with naked eye and hand lens to quantify and correlate ligature mark with its appearance in relation to material, impression, pattern, color (to evaluate time since death), course, type of knot, level of ligature, skin changes etc. A note was also made regarding other external injuries, if any. Thus, after completing external examination autopsy was performed with dissection of thoraco abdominal and cranial cavities followed by dissection of neck with ' $\mathrm{Y}$ ' shaped incision. Two incisions were given over either side of neck $2-3 \mathrm{cms}$ behind lobe of each ear converging diagonally at manubrium sterni. The incision was continued down as a single line up to pubic symphysis. The neck dissection was completed by layer wise inspection starting with subcutaneous tissue and proceeding with muscle layers, vital vessels and other deeper structures in the neck beneath ligature mark. All gross findings were noted and a portion of skin and subcutaneous tissue from the site of ligature mark was excised. The excised specimen was preserved in $10 \%$ formalin and subjected for histopathological examination. The sections were stained with hematoxylin and eosin and slides were examined by a panel of pathologists. The final opinion was recorded and findings were correlated in all the cases for further evaluation.

\section{Results}

The total numbers of autopsies conducted in mortuary at S.V.Medical College, Tirupati from January 2010 to December 2013 were 3660 . Amongst the above 83 (2.26\%) cases of asphyxial deaths due to hanging were notified. All the cases were examined with emphasis on ligature mark - gross and histopathological examination. The year wise percentage of hanging cases was estimated and it seems to be almost constant ranging from $0.4 \%$ to $0.6 \%$. More number of cases were reported in 2011 $-24(28.91 \%)$ (Figure 1). 


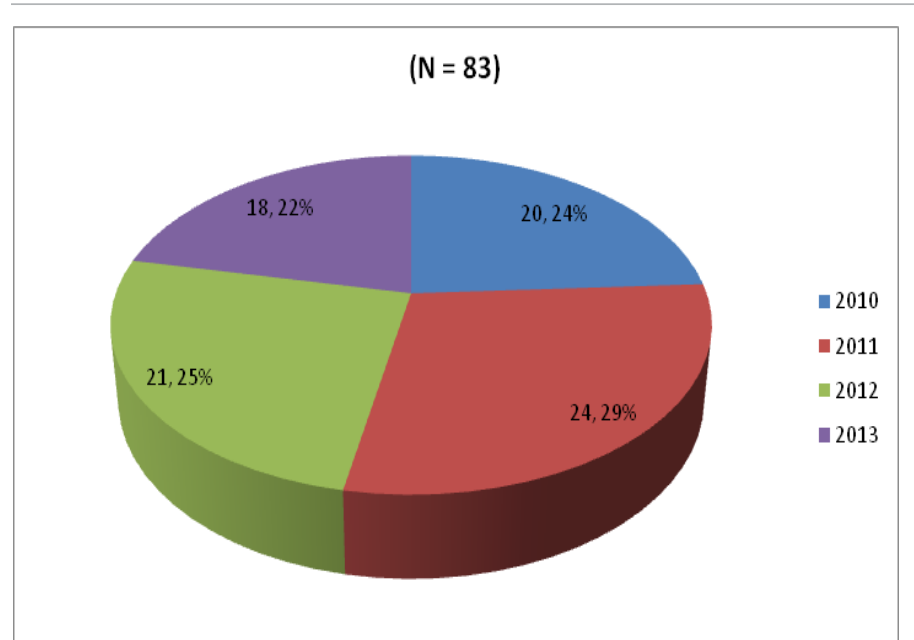

Figure 1: Number of Deaths due to hanging from January 2010 to December 2013 (4 years) - year wise distribution

Majority of cases observed were young adults in third decade i.e., 21-30 years - 37 (44.5\%) followed by individuals in fourth decade i.e., 31-40 years - $18(21.6 \%)$. In the present study $52(62.6 \%)$ male victims and $31(37.3 \%)$ female victims were found. Majority of male and female cases belong to third decade, $28.91 \%$ and $15.6 \%$ respectively (Table 1). Amongst 83 cases of hanging $33(39.75 \%)$ males were married individuals and $11(13.25 \%)$ were unmarried. In $8(9.63 \%)$ the marital status was not known. Whereas, 19 (22.89\%) female victims were married, 10(12.04\%) unmarried and the status were not known in $2(2.4 \%)$ cases.

Table 1: Age \& Sex Wise Distribution of Cases

\begin{tabular}{|c|c|c|c|c|}
\hline Sl.no & $\begin{array}{c}\text { Age in } \\
\text { years }\end{array}$ & $\begin{array}{c}\text { Male } \\
\mathbf{n}(\%)\end{array}$ & $\begin{array}{c}\text { Female } \\
\mathbf{n}(\mathbf{\%})\end{array}$ & $\begin{array}{c}\text { Total } \\
\mathbf{n}(\%)\end{array}$ \\
\hline 1. & $0-10$ & $0(0)$ & $1(1.2)$ & $1(1.2)$ \\
\hline 2. & $11-20$ & $7(8.4)$ & $5(6)$ & $12(14.4)$ \\
\hline 3. & $21-30$ & $24(28.91$ & $13(15.6)$ & $37(44.5)$ \\
\hline 4. & $31-40$ & $12(14.4)$ & $6(7.2)$ & $18(21.6)$ \\
\hline 5. & $41-50$ & $6(7.2)$ & $3(3.6))$ & $9(10.8)$ \\
\hline 6. & $51-60$ & $2(2.4)$ & $2(2.4)$ & $4(4.8)$ \\
\hline 7. & $61-70$ & $0(0)$ & $1(1.2)$ & $1(1.2)$ \\
\hline 8. & $71-80$ & $1(1.2)$ & $0(0)$ & $1(1.2)$ \\
\hline & Total & $\mathbf{5 2}(\mathbf{6 2 . 6 )}$ & $\mathbf{3 1}(\mathbf{3 7 . 3})$ & $\mathbf{N = 8 3 ( 1 0 0 )}$ \\
\hline
\end{tabular}

Most of the victims belong to middle and lower socio economic strata - 37(45\%) and $36(43 \%)$ respectively. The status was not known in $10(12 \%)$ cases and there were no cases from upper social status.

As far as the type of hanging was concerned, complete hanging was observed in $76(91.56 \%)$ cases. Partial hanging was seen in $7(8.43 \%)$ cases and in $5(6.02 \%)$ cases feet was seen touching the ground. In $2(2.40 \%)$ cases knees were touching the ground.

The ligature material was found in all the cases examined. Chunni was the most common ligature material used by victims in present study $-25(31.12 \%)$, followed by nylon rope in $15(18.07 \%)$ and other materials like saree, bed sheet etc., were also used (Table 2). An unusual plastic tape like material was observed in one case. (Figure 2)
Table 2: Ligature Material(s) used in cases of Hanging

\begin{tabular}{|c|l|c|c|}
\hline Sl.no & \multicolumn{1}{|c|}{ Ligature material } & $\begin{array}{c}\text { No. of cases } \\
(\mathbf{N}=\mathbf{8 3})\end{array}$ & $\begin{array}{c}\text { Percentage } \\
(\mathbf{\%})\end{array}$ \\
\hline 1. & Chunni & 25 & 30.12 \\
\hline 2. & Nylon rope & 15 & 18.07 \\
\hline 3. & Saree & 14 & 16.86 \\
\hline 4. & Jute rope & 13 & 15.66 \\
\hline 5. & Bedsheet & 6 & 7.22 \\
\hline 6. & Electric insulation wire & 5 & 6.02 \\
\hline 7. & Newar cloth & 3 & 3.61 \\
\hline 8. & Newar plastic & 1 & 1.20 \\
\hline 9. & Plastic tape material & $\mathbf{8 3}$ & 1.20 \\
\hline & Total & & $\mathbf{1 0 0}$ \\
\hline
\end{tabular}

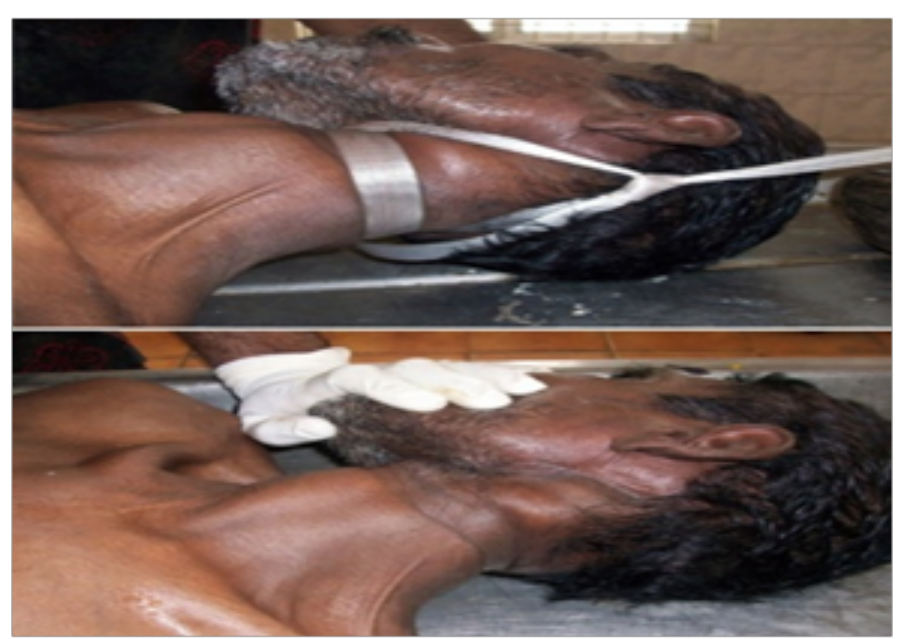

Figure 2: Plastic tape material and pattern of ligature material over the neck.

The pattern of ligature mark was present in $12(14.45 \%)$ cases. A single ligature mark was found in $80(96.38 \%)$ and multiple rows in $3(3.61 \%)$ cases. In present study two types of knots were found. Slip knot was found in 15 (18.07\%) and fixed knot in $9(10.84 \%)$ cases. There was no particular knot in 59 $(71.08 \%)$ cases, where, a simple loop, encircled ligature material etc., were observed.

The ligature mark was situated above thyroid cartilage in $76(91.56 \%)$ cases, at the level of thyroid cartilage in 5 $(6.02 \%)$ cases and below thyroid cartilage in $2(2.40 \%)$ cases. Complete encirclement of mark around the neck was observed in $12(14.45 \%)$ cases and partial encirclement of neck in 71 $(85.54 \%)$ cases.

Dribbling of saliva was observed in $27(32.53 \%)$ cases. Bleeding from mouth and nose was seen in $2(2.40 \%)$ cases only. Grooving of the ligature mark (Figure 3) over the skin of neck was present in $19(22.89 \%)$. It was absent in $64(77.10 \%)$ cases. A single case amongst all the examined cases shows fractured hyoid bone $(1.20 \%)$. 


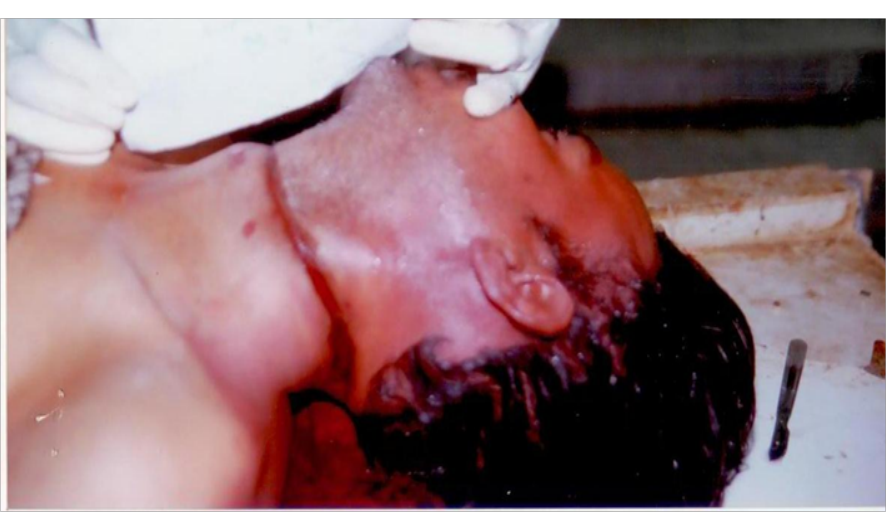

Figure 3: Grooving and brownish discolouration of the skin over the neck

In the present study it was observed that in $3(3.61 \%)$ cases external injuries other than ligature mark were present. Soft tissue injuries were observed in 23 (27.71\%) cases, which show pale, white and glistening structures with focal engorged capillaries and small areas of hemorrhagic collections in the muscle plane and fibro fatty tissue (Figure 4). In rest of the $60(72.28 \%)$ cases; the internal examination was normal without any gross abnormalities. Histopathological evaluation was performed in all 83 cases. Three characteristic skin changes and three salient features of subcutaneous and soft tissues were recorded (Table 3 ). Discontinuity of epidermal and dermal layers of skin (breaking) was noticed in $21(25.30 \%)$ cases. Increased waviness of epidermal and dermal layers of skin (wrinkling) was noticed in $30(36.14 \%)$ cases. There was decreased skin thickness with increased basophilia (compression) in $28(33.73 \%)$ cases. All the three features were notified in $4(4.81 \%)$ cases. Only congestion of underlying tissues was observed in 35 (42.16\%); hemorrhagic collection was noticed in $18(21.68 \%)$; congestion of tissues and frank areas of hemorrhages were seen in $6(7.22 \%)$ cases and congestion along with frank hemorrhages and cellular infiltrates were found in $8(9.63 \%)$ cases. All the above findings were absent in $16(19.27 \%)$ cases (Figures $5 \& 6)$.

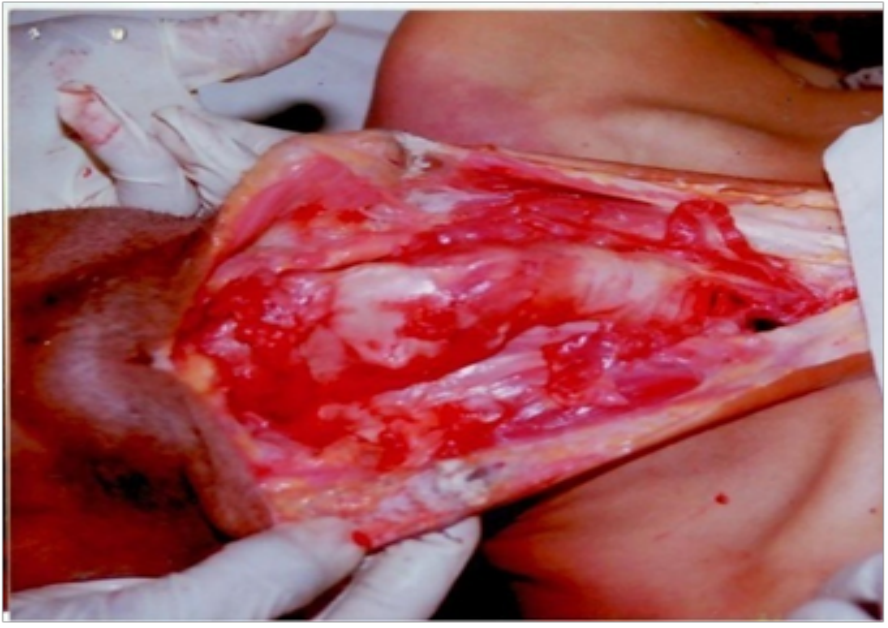

Figure 4: internal examination of neck structures beneath the ligature mark showing large hemorrhage
Table 3: Microscopic Changes in cases of Hanging

\begin{tabular}{|c|l|c|c|}
\hline Sl.no & \multicolumn{1}{|c|}{ Microscopic detail } & $\begin{array}{c}\text { No. of cases } \\
(\mathbf{N}=\mathbf{8 3})\end{array}$ & $\begin{array}{c}\text { Percentage } \\
(\%)\end{array}$ \\
\hline Skin changes:- & \multicolumn{2}{|l|}{} \\
\hline 1. & Breaking & 21 & 25.30 \\
\hline 2. & Wrinkling & 30 & 36.14 \\
\hline 3. & Compression & 28 & 33.73 \\
\hline 4. & All the three & 4 & 4.81 \\
\hline Internal neck structures :- & 35 & 42.16 \\
\hline 1. & Congestion & 18 & 21.68 \\
\hline 2. & Hemorrhage & 8 & 9.63 \\
\hline 3. & Congestion + Hemorrhage & 8 & 9.63 \\
\hline 4. & $\begin{array}{l}\text { Congestion + Hemorrhage } \\
\text { + Cellular infiltration }\end{array}$ & 16 & 19.27 \\
\hline 5. & None of the above & \multicolumn{2}{|l}{} \\
\hline
\end{tabular}

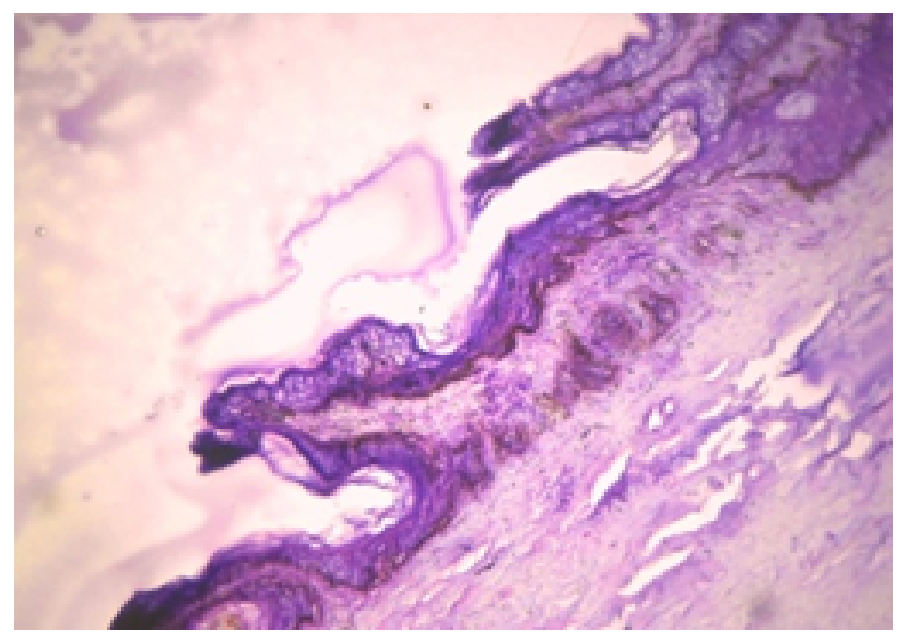

Figure 5: Microscopic examination (10x). Wrinkling and breaking of skin

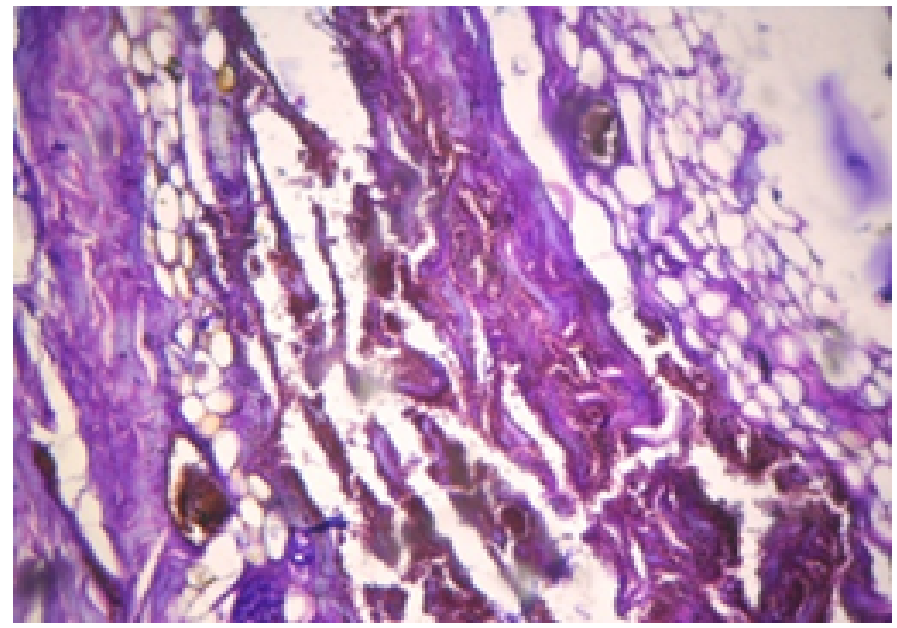

Figure 6: Subcutaneous haemorrhages at the plane of ligature (10x)

\section{Discussion}

The ligature mark in hanging needs detailed and extensive examination. Inspection, palpation and internal examination followed by histopathological examination have to be car- 
ried out in an orderly manner. The nature and texture of ligature material, type of hanging (complete / partial) also plays a vital role in correlating the findings in respective cases. In majority of cases partial examination or missing of some trivial but important findings leads to derivation of wrong and inconclusive evidences which in turn leads to confusion ${ }^{[12]}$.

In present study $2.26 \%$ of cases of hanging were recorded in a period of four years (January 2010 to December 2013). There was gradual raise in number of cases from 2010 with dipping in 2012 and further increase in 2013. The above statement clearly depicts that, the number of cases of hanging are increasing and there is a definite need for formulation of necessary steps to control this social evil.

Young adults in third decade accounted for maximum number of cases $-44.5 \%$ followed by fourth decade $-21.6 \%$. Similar findings were observed by various research workers and authors $^{[2,6,7,12-15]}$.

Majority of cases were males $-62.6 \%$ and $36.3 \%$ of cases were females. More number of male victims was found to be in their third decade $-28.91 \%$ and majority of female victims also were in their third decade $-15.6 \%$. The present findings are consistent with studies done by other authors ${ }^{[6,7,12-14,16]}$.

The incidence of hanging was found to be more common in married individuals, $37.75 \%$ of males and $22.89 \%$ of females were married individuals. Similar findings were observed in study done by Saisudheer and Nagaraja ${ }^{[2]}$. But there was discrepancy regarding distribution of sex. As in present study majority of cases were married males, whereas, married females were found to be more common group in study done by Saisudheer and Nagaraja ${ }^{[2]}$. The possible element of stress and increasing responsibilities after marriage can be attributed regarding increase in the cases of married males. Middle and lower income group is hardly hit in the society. Thus, $45 \%$ of cases belong to middle socioeconomic strata and $43 \%$ of cases were from lower socioeconomic strata. The observations correlated with the findings of Saisudheer and Nagaraja ${ }^{[2]}$. Family related issues, financial derailments and other miscellaneous reasons play a pivotal role leading to psychological breakdown and increased suicidal tendencies in the pupils of middle and lower socioeconomic strata.

In the present study, maximum number of cases showed complete hanging $(91.56 \%)$ which is similar to observations by Saisudheer and Nagaraja ${ }^{[2]}$. Death by complete hanging might be ascribed to firm motive to commit suicide in an individual.

The authors tried to study in detail regarding ligature material used and comparative study was performed in order to assess the common material used during hanging by the victims in Indian subcontinent. In all the studies done by various researchers, cloth material - chunni was found to be the commonest ligature material followed by nylon rope and saree ${ }^{[6,7]}$. The comparative results are tabulated in table 4 .
Table 4: Comparison with other studies regarding Ligature material(s) used in cases of Hanging.

\begin{tabular}{|c|c|c|c|c|}
\hline Sl.no & Ligature Material & $\begin{array}{l}\text { Present } \\
\text { Study } \\
(\%)\end{array}$ & $\begin{array}{l}\text { Sadikhusen } \\
\text { et al.,[6] } \\
(\%)\end{array}$ & $\begin{array}{l}\text { Sharma et } \\
\text { al.,[7] } \\
(\%)\end{array}$ \\
\hline 1. & Chunni & 30.12 & 34.44 & 30.9 . \\
\hline 2. & Nylon rope & 18.07 & 31.10 & 18.18 \\
\hline 3. & Saree & 16.86 & 16.66 & - \\
\hline 4. & Jute rope & 15.66 & - & 12.73 \\
\hline 5. & Bedsheet & 7.22 & - & 16.36 \\
\hline 6. & $\begin{array}{l}\text { Electric insulation } \\
\text { wire }\end{array}$ & 6.02 & - & 5.46 \\
\hline 7. & Newar cloth & 3.61 & - & 7.27 \\
\hline 8. & Newar plastic & 1.20 & - & \\
\hline 9. & Plastic tape material & 1.20 & - & - \\
\hline 10. & Others & - & $\begin{array}{c}16.66 \text { (cot- } \\
\text { ton rope) }\end{array}$ & $\begin{array}{c}1.82+7.27 \\
\text { (shawl + cable } \\
\text { wire) }\end{array}$ \\
\hline 11. & Not known & - & - & 39.56 \\
\hline
\end{tabular}

Numerous facts can be established by examining ligature material. It produces a particular pattern over the skin and the characteristics of the mark broadly depend on material used. As per the above tabular column, common household material is being used for hanging in majority of individuals. Thus, it depicts that in majority of cases the decision of committing suicide by hanging is an unplanned one under extreme psychological disturbances. In particular period of time whatever material was available it has been used by the victims.

The pattern of ligature marks was observed only in $14.45 \%$ which correlates with study done by Saisudheer and Nagaraja $^{[2]}$, where the pattern was observed in $10 \%$.

Single ligature marks was most commonly found in $96.38 \%$ of cases. Identical results were recorded by Sadikhusen $e t a l^{[6]}$. In majority of cases there was not particular kind of knot $(71.08 \%)$, which is contradictory finding compared to the findings of Sadikhusen et al ${ }^{[6]}$ where fixed knot was observed in maximum number of cases - 58\%. Thus, the fact is once again strengthened, that in majority of individuals suicide by hanging is being practiced under extreme psychological stress where individual was not able to device a knot at that instance.

In present study maximum number of cases $(91.56 \%)$ showed ligature mark above thyroid cartilage which was also observed by Saisudheer and Nagaraja (88\%), Sharma et al., (85\%), Mohammed Musaib et al, (72.09\%) and others[ [2,6,7,17-22]. In hanging the ligature mark was normally situated higher in the neck above laryngeal prominence. The position of mark in hanging depends on the way - the devise was fixed and the suspension point ${ }^{[23]}$. According to Reddy KSN, the mark of hanging is situated above the level of thyroid cartilage in between larynx and chin in $80 \%$, at the level of thyroid cartilage in $15 \%$ and below the level of thyroid cartilage in about $5 \%$ cases, that too in case of partial hanging ${ }^{[22]}$. All the above facts are correlating with the observations in present study.

Dribbling of saliva was found in $32.53 \%$ victims. Similar findings were observed in the studies performed by various researchers ${ }^{[17,24]}$. Dribbling of saliva is a definite sign of hanging having taken place during life. The above statement was jus- 
tified and strengthened by studies performed by Paliwal PK et al on reconstructive forensic medicine ${ }^{[25]}$. Bleeding from mouth and nose were observed in $2.40 \%$ only, which is consistent with observations of Mohammed Musaib et al, ${ }^{[17]}$ and Sarangi M.P et $a l^{[26]}$. Even though bleeding from orifices does not play a major role during investigation in case of hanging, it is considered as one of the signs of asphyxia and helps to relate the posture of the victim at the time of hanging.

Majority of cases showed partial encirclement of rope around the neck $(83.54 \%)$, which was consistent with observations of Sadikhusen et al., ${ }^{[6]}-80 \%$ and Sharma et al., ${ }^{[7]}-93 \%$. In most of the cases grooving of the ligature over the skin of neck was absent $(77.10 \%)$. Contradicting feature was appreciated by Saisudheerand Nagaraja., ${ }^{[6]}$ where grooving was present in $54 \%$ of cases.

In present study, incidence of fracture of hyoid bone was observed in only one case (1.20\%). In other studies also the percentage of cases showing hyoid bone fracture was very less. In a study conducted by Tripude B.H. et al., ${ }^{[2]}$ there was increased incidence of hyoid bone fracture. Comparative analysis is tabulated in table: $5^{[2,14,17,26-28]}$.

Table 5: Comparison with other studies regarding the Hyoid Bone Fracture in cases of Hanging.

\begin{tabular}{|c|l|c|}
\hline Sl.no & \multicolumn{1}{|c|}{ Authors } & $\begin{array}{l}\text { Percentage of cases } \\
\text { showing hyoid bone } \\
\text { fracture (\%) }\end{array}$ \\
\hline 1. & Present study & 1.20 \\
\hline 2. & Sarangi et al., ${ }^{[26]}$ & 9.4 \\
\hline 3. & Tripude BH et al., ${ }^{[27]}$ & 64.51 \\
\hline 4. & Sheikh et al., ${ }^{[14]}$ & 5.08 \\
\hline 5. & Meera et al., ${ }^{[27]}$ & 3.57 \\
\hline 6. & Mohammed Musaib et al., ${ }^{[17]}$ & 11.63 \\
\hline 7. & Saisudheer and Nagaraja ., ${ }^{[2]}$ & 4.0 \\
\hline
\end{tabular}

In present study, very few cases showed external injuries other than ligature mark (3.61\%). Similar observations were evident in studies done by Saisudheer and Nagaraja ${ }^{[2]}$.

Internal examination was carried out and soft tissue injuries like congestion of neck structures, internal capillary hemorrhages and frank hemorrhagic areas were observed in $27.71 \%$ cases which were found out to be consistent with the findings of Saisudheer and Nagaraja ${ }^{[2]}$. It is said that ligature mark is mainly a postmortem phenomenon, any inner neck structure injury indicating ligature mark intravitality is to be identified to establish the antemortem hanging ${ }^{[4]}$.

An array of microscopic characteristic changes was studied. Skin changes - breaking (25.30\%), wrinkling $(36.14 \%)$ and compression (33.73\%) were recorded and were found to be correlating with study done by Anil yadav and Gupta ${ }^{[12]}$, where, breaking (35.16\%), wrinkling (46.15\%) and compression (43.95\%) was observed. Congestion of blood vessels (42.16\%), hemorrhages (21.68\%), cellular infiltration (9.63\%) was observed in present study. In a study carried by Anil yadav and Gupta $^{[12]}$ - congestion (5.27\%), hemorrhage (20.8\%), cellular infiltration (32.9\%) were observed and showed close correlation with present study. The microscopic features were uneventful in $19.27 \%$ cases and a similar observation was made by Anil yadav and Gupta ${ }^{[12]}$ where $18.6 \%$ cases were uneventful. Tissue reaction if present indicates ante mortem hanging. The absence of tissue reaction does not exclude antemortem hanging ${ }^{[22]}$.

Thus, various features of external mechanical injuries, internal examination with assisted microscopic examination was performed and all findings were correlated. All the observations were linked with respective subsequent findings to obtain an acceptable outcome regarding the mode and manner of death in the victim.

\section{Conclusion}

The present study tries to emphasize that, the ligature mark needs to be evaluated along with other external features, internal findings and histopathological features. Thus, if this procedure of linking all the findings is followed as a routine practice in cases of death due to hanging the formulation of final opinion in doubtful cases also will become easy. This in turn helps to distinguish ante mortem ligature mark with post mortem ligature mark and to establishing the cause and mode of death. Hence, a perfect pathway can be made out to derive appropriate means in the administration of justice.

\section{Conflict of Interest: None}

\section{References}

1. Suicides in India. The Registrar General of India. (2012) Government of India.

2. Saisudheer, T., Nagaraja, T.V. A study of ligature mark in cases of hanging deaths. (2012) Int J Pharm Biomed Sci 3(3): 80-84. 3. Adelson, L. The Pathology of homicide. (1974) Charles C Thomas Publisher, Springfield 547-553.

4. Sharma, B.R., Singh, V.P., Harish, D. Neck structure injuries in hanging - comparing retrospective and prospective studies. (2005) Med Sci Law 45(4): 321-330.

5. Mathiharan K., Patnaik A.K. Death from asphyxia. In: Modi, editor. Modi‘s Medical Jurisprudence and Toxicology, 23rd ed. New Delhi, India (2005) Lexis Nexis Butterworth 565.

6. Sadikhusen, G. M., Hari, M. M., Hetal, C. K., et al. Pattern of ligature mark in cases of compressed neck in Rajkot region: A prospective study. (2012) J Indian Acad Forensic Med 34(1): 40-43.

7. Sharma, B.R., Harish, D., Singh, V.P., et al. Ligature mark on neck: How informative?. (2005) JIAFM 27(1): 10-15.

8. Polson, C.J. The essentials of forensic medicine, 2nd Ed, (1965) Charles C Thomas Publishers 300

9. Paparo, G.P., Siegel, H. Neck markings and fractures in suicidal hanging. (1984) Forensic Sci Int 24(1): 27-35.

10. Taylor, A.S. Principles and Practice of Medical Jurisprudence. Edited by Keith Mant A. 13thed (1994) 316.

11. Gordon, I., Shapiro, H. A., Brenson, S. D. Forensic Medicine - A guide to principles. (1988) Churchill Livingstone, New York, 3rd ed 108-12.

12. Yadav, A., Gupta, B.M. Histopathological changes in skin and subcutaneous tissues at ligature site in cases of hanging and strangulation. (2009) J Indian Acad Forensic Med 31(3): 200204

13. Luke, J. L. Correlation of circumstances with pathological findings in Asphyxial deaths by hanging. (1985) J Forensic Sci 
30(4): 1140-1147.

14.Sheikh, M.I., Agarwal, S.S. Medico-legal implications of hyoid bone fracture- a study paper. (2001) J Indian Acad Forensic Medicine 23: 61-63.

15. Rajeev, J., Ashok, C., Hakumal, R. Incidence and Medico-legal importance of Autopsy study of fracture of Neck structure in hanging and strangulation. (2007) Medico legal update 7(4): 105-109.

16. Jani, C.B., Gupta, B.D. An autopsy study of parameter influencing injury to osteocartilaginous structures of neck in hanging. (2002) International Journal of Medical Toxicology \&Legal Medicine 5(1): 4-7.

17. Shaikh, M. M. M., Chotaliya, H.J., Modi, A.d., et al. A study of gross postmortem findings in cases of hanging and ligature strangulation. (2013) J Indian Acad Forensic Med 35(1): 63-65. 18. Knight, B. Forensic Pathology (1996) Arnold Publication 2nd ed. 361-89

19.Modi, J.P. Modi`s Medical Jurisprudence \& Toxicology, Butterworth's, India, New Delhi. 22nd ed. by Subramanian BV (1988) 251-272.
20. Nandy, A. Principle of Forensic Medicine (2000) New Central Book Agency Pvt. Ltd, Calcutta, 2nd ed. 315-323.

21. Reddy, K.S.N. The Essential of Forensic Medicine \& Toxicology, Published by K. Suguna Devi, Hyderabad (2000) 19th ed. 283-295.

22. Jason, P.J., Anthony, B., William, S. Forensic Medicine-Clinical and Pathological Aspects, Greenwich Medical Media Ltd, London, 2003; 1st ed. 266-269.

23. Samanta, A.K., Nayak, S.R. Newer trends in hanging death. (2012) J Indian Acad Forensic Med 34(1): 37 - 39.

24. Paliwal, P. K., Sirohiwal, B., Khanagwal, V.P., et al. A drop of saliva de-codes the mystery of hanging body. (2011) J Indian Acad Forensic Med 33(3): 280-282.

25. Sarangi, M. P. "Ligature mark/s" - In Forensic pathologist's perspective. (1998) Journal of Forensic Medicine and Toxicology $15: 99-102$.

26. Tripude, B. H., Murkey, P. N., Pawar, V. G. Profile of Hanging Cases on Autopsy at a Tertiary Care Hospital In Central India. (2010) Journal of Karnataka Medico-legal Society 19: 3-7. 27. Meera, Th., Singh, M. B. K. Pattern of neck findings in suicidal hanging. (2011) J Indian Acad Forensic Med 33: 350-352.
Ommega Online Publishers

Journal Title: Journal of Addiction and Dependence(JAD)

Journal Short Name: J Addict Depend
ISSN no: 2471-061X

E-mail: addiction.depend@ommegaonline.org

Website: www.ommegaonline.org 